\title{
Geometry Concepts in Mathematics Perceived Difficult To Learn By Senior Secondary School Students in Ekiti State, Nigeria
}

\author{
Fabiyi, T.R. \\ $\%$ Department of Science Education, University of Ilorin, Ilorin, Nigeria.
}

\begin{abstract}
The study focused on geometry concepts in mathematics perceived difficult to learn by senior secondary school students in Ekiti State, Nigeria. 500 senior secondary school two (SS2) students made up of 228 males and 272 females from thirty (30) co-educational schools in Ekiti State, Nigeria constituted the sample for the study using proportionate and random sampling techniques respectively. A 23-item Questionnaire on Geometry Concepts in Mathematics Perceived Difficult was used as instrument for the study. Three research questions were answered using frequency counts and percentages while the only formulated hypothesis was tested using chi-square $\left(\chi^{2}\right)$ statistics. The findings revealed that, out of 23 concepts, eight concepts were perceived difficult to learn by students which includes: Construction, coordinate geometry, circle theorem and so on and reasons given for perceiving geometry concepts difficult includes: Unavailability of instructional materials, teachers' method of instruction and so on. Also, students' gender had a great influence on the learning of concepts in geometry at 0.05 level of significant in favour of female students. It is therefore recommended that the identified difficult geometry concepts in mathematics should be taught by using appropriate teachers' method of instruction and instructional materials.

Keywords: Geometry Concepts, Concepts perceived difficult, Concepts perceived not difficult
\end{abstract}

\section{Introduction}

Mathematics is a compulsory subject that cuts across every other field. According to Ayinla (2011), mathematics is the pillar of all knowledge showing its relevance to all disciplines. Michael (2008) described mathematics as a relationship between numbers and other measurable quantities. Mathematics is also the language of science that allows scientists to communicate ideas using universally accepted terminologies. Soyemi and Jegede (2000) defined mathematics as the science of structure, order, numbers, space and quantity. The authours further affirm that mathematics is a relationship that revolves around the elementary practice of counting, measuring and description of shapes and objects. Douglas (2009) expressed mathematics as the orderly study of the structures and pattern of entities. According to Salman (2005), mathematics is an indispensable tool in the study of sciences, humanities and technology.

The role of mathematics in any society cannot be over-emphasized because of its importance in national development. National Policy on Education FRN (2013) submitted that mathematics is one of the core subjects offered by all students at both junior and senior secondary schools. Without passing mathematics at the senior secondary school, it is almost difficult if not impossible to gain admission into higher institution (Kekere, 2008). Adegun and Adegun (2013) emphasized the need to make mathematics a compulsory subject at both primary and secondary school levels if scientists, technologist and engineers are to be produced in our universities; teaching and learning of mathematics should be taken very seriously. According to Betiku (2000), Science, Technology and Mathematics education have been widely acclaimed to be the index of measuring any nation's socio-economic and geo-political development.

Despite the relative importance of mathematics, students' performance in the subject in West African Examinations Council (WAEC) has remained consistently poor (National Mathematical Centre, 2009). Amazigo (2000) opined that mathematics educators have put up noble and spirited efforts aimed at identifying the major problems associated with the teaching and learning of mathematics such as poor background in mathematics, lack of incentives for teachers, unqualified teachers in the system and lack of learner's interest. Also, students' perception that it is difficult, large classes and psychological fear of the subject was furthered identified as factors responsible for the poor performance in the subject. In spite of all these noble efforts, the problem of poor achievement in mathematics has continued to rear its head in the nation's public examinations.

The West African Examinations Council (WAEC) Chief Examiners' Reports May/June (2007, 2008, 2009, 2010 and 2011) identified geometry as one of the branches of mathematics in which students have not been performing satisfactorily.

Geometry is a branch of mathematics which deals with the study of different shapes or figures and their properties (Paulina, 2007). Geometry could be a plane or solid shape and their properties. The plane shape is a geometrical object with length and width/ breadth or base and height/ altitude. Plane shapes are also called 2dimensional shapes such as square, rectangle, circle, polygon, triangle, and so on. A solid shape is a geometrical 
object with length, breadth and height or base area and height. Solid shapes are also called 3-dimensional shapes such as a cone, pyramid, sphere, cylinder, prism, cube, and cuboid and (Salman, 2009).

Geometry plays a significant role in primary and secondary schools mathematics curricula in Nigeria and other countries. It provides a rich source of visualization for understanding arithmetical, algebraic, and statistical concepts (Battista, 1999). Also, Volderman (1998) expressed that geometry provides a complete appreciation of the world we live in. Geometry appears naturally in the structure of the solar system, a geological formation, rocks and crystals, plants and flowers, and even in animals. It is also a major part of the synthetic world such as art, architecture, cars, machines, and virtually everything humans create. In the same vein, studies revealed that geometry is applicable and relevant to employment in everyday live, other subjects in the curriculum such as science, arts, and technology. Also, geometry is used to develop students' spatial awareness, intuition, visualizations and to solve practical problems and so on (Sunsuma, Masocha \& Zezekwa, 2012).

In spite of these important, a thorough research revealed the factors that are responsible for students' difficulty in learning geometry to include: lack of proof by students, lack of background knowledge, poor reasoning skill in geometry, geometric language comprehension, lack of visualizing abilities, teachers' method of teaching, non-availability of instructional materials, lack of proof by students, gender differences among others ( Mason, 2002; Noraini, 2006; Uduosoro, 2011; Telima, 2011 and Aysen, 2012).

According to Nigerian Educational research and Development Council (2012), observed that difficult concepts in mathematics referred to any concept that posed challenges to teachers and learners. Empirical studies on perceived difficult concepts in mathematics have been addressed by some researchers. Salman (2005) carried out a study on difficulty levels of topics in the primary school mathematics curriculum. Azuka, Jekayinfa, Durojaye and Okwoza (2013) worked on difficulty levels of topics in the new senior secondary school mathematics curriculum. Also, Adegun and Adegun (2013) investigated students and teachers' view of difficult areas in mathematics syllabus. In the same vein, Uduosoro (2011) conducted a study on students' perceived and actual learning difficulties in secondary school mathematics. Abdul-Raheem (2012) carried out a study on ratings of the difficulty levels of senior school mathematics topics by teachers and students.

Several studies have been conducted to determine influence of gender on perceived difficult geometry concepts in mathematics. Baharvand (2001) and Uduosoro (2011) found that male students performed better than female students on difficult geometry concepts in mathematics. Etekudo (2002) and Ominrin (2009) argued that female students performed better than male students at computation and spatial visualization. Olagunju (2001), Gbodi and Olaleye (2006) and Adegun and Adegun (2013) found that there is no disparity in the performance of male and female students in geometry.

\subsection{Statement of the Problem}

Studies have revealed that difficulty in teaching and learning of mathematics especially geometry has resulted in mass failure in examinations (NMC, 2009). Adegun and Adegun, (2013) stated that students generally encountered difficulties in geometry and performed poorly in senior secondary school mathematics lesson. Also, Telima (2011) found out that many students fail to grasp key concepts in geometry and leave mathematics classes without learning the basic terminology.

Findings have shown that some factors are identified to make the learning of geometry concepts in mathematics difficult which include: teachers' methods of instruction, geometric language, visualizing abilities (Noraini, 2006 and Aysen, 2012). Other factors include: non-availability and obsolescence of instructional materials, gender differences, poor reasoning skill, inadequate time, inadequate school curriculum and lack of proof by students (Mason, 2002; Uduosoro, 2011 and NERDC, 2012). All these are believed to have a negative effect on the learning of geometry.

Learning of mathematics in particular geometry is believed to be determined by gender differences. It has caused a lot of controversies in the sense that researchers such as Adebule (2004) opined that gender has no specific effect on the learning of mathematics while Udousoro (2011) was of the opinion that mathematics is male gender friendly. Abiam and Odok (2006) found no significant relationship between gender and achievement in number and numeration, algebraic processes and statistics. The researchers, however, found the existence of a weak significant relationship in geometry and trigonometry.

According to WAEC Chief Examiners' Report (2007, 2008, 2009, 2010 and 2011), confirmed that candidates had weaknesses in mensuration, construction, circle theorems and so on. All these make students perform woefully in the examinations; this poor performance of students in mathematics especially in geometry has been a thing of concern to mathematics educators, parents and governments (Burton, 1999). Consequently, research findings have confirmed that geometry is one of the topics among the abstract and complex aspects of mathematics that students find difficult to learn (Akinlade, 2004).

Based on these findings, students have not been performing well in mathematics especially on geometry. Also, none of the literature reviewed in this study addressed specifically geometry concepts in 
mathematics perceived difficult to learn by students. This present study identified geometry concepts in mathematics perceived difficult to learn by senior secondary school students in Ekiti State, Nigeria. Also, the causes of the perceived difficulty of geometry concepts, the degree of the level of difficulty of geometry concepts and the influence of gender on students' perception of difficult geometry concepts were considered.

\subsection{Purpose of the Study}

The purpose of this study was to identify geometry concepts in mathematics perceived difficult to learn by senior secondary school students in Ekiti State, Nigeria.

Specifically, this study sought to:

1. Identify the geometry concepts perceived difficult to learn;

2. analyse the plausible causes of the perceived difficulty of geometry concepts;

3. find out the degree of the level of difficulty of geometry concepts; and

4. The influence of gender on students' perception of difficult geometry concepts.

\subsection{Research Questions}

In this study, answers were provided to the following research questions:

1.What are the geometry concepts perceived difficult to learn by senior school students in Ekiti State, Nigeria?

2. What are the plausible causes of the perceived difficulty of geometry concepts?

3. What is the degree of the level of difficulty of geometry concepts?

4. Does gender influence students perception of difficult geometry concepts?

\subsection{Research Hypothesis}

Based on the research questions raised, the null hypothesis was formulated and tested for the study:

$\mathrm{HO}_{1}$ : There is no significant difference in the number of geometry concepts perceived difficult by male and female students.

\section{Methodology}

2.1 Research Type: The study was a descriptive and a survey type because a questionnaire was used to collect information on the geometry concepts in mathematics perceived to be difficult.

\subsection{Population, Sample and Sampling Techniques}

The population for this study was all students in senior secondary school in Ekiti State. The target population was all the senior secondary school two (SS2) students. The study employed a multistage sampling technique. The first stage involved the random sampling technique of thirty (30) senior secondary schools from three senatorial district of Ekiti- State. However, the second stage involved proportionate sampling technique of five hundred (500) students from senior secondary school two (SS2) in three senatorial districts of Ekiti-State. In selecting the participating students, 200 (40\%) was selected from Ekiti Central, 160 (32\%) was selected from Ekiti South and 140 (28\%) from Ekiti North.

\subsection{Research Instrument}

The research instrument for this study was a researcher-developed questionnaire entitled: Questionnaire on Geometry Concepts in Mathematics Perceived Difficult (QGCMPD) which consisted of three sections. Section A consisted of respondents' personal Information, Section B contained twenty-three (23) concepts in geometry collected from the senior school mathematics curriculum from which the students were to identify concepts perceived difficult to learn. There were four (4) alternative responses: very difficult, difficult, moderately difficult and not difficult while Section C contained statements on reasons why the concepts were perceived difficult to learn.

\subsection{Validation of the Research Instrument}

The instrument was subjected to both face and content validity. The questionnaire was given to two experienced mathematics teachers for proper scrutiny of the instrument. Comments of the researcher's supervisor and two other lecturers in the Department of Science Education, University of Ilorin were considered before the production of the final draft.

The reliability of the instrument was determined by test re-test method with an interval of three weeks. The instrument was trial tested on fifty (50), students from five non- participating schools in the interval of three weeks. The data collected was subjected to Pearson product moment correlation coefficient to obtain the reliability index at 0.05 significant. This gave a coefficient of 0.70 which was felt good for the study. 


\subsection{Procedure for Data collection}

The researcher personally sought the permission of the managements of the selected schools by presenting the letter of introduction signed by the Head of Department (HOD) of Science Education, University of Ilorin, Ilorin, Nigeria. The consent and co-operation of mathematics teachers of the students that participated in the study, the consent and cooperation of students that participated in the study and their parents were all sought before carrying out the study. The researcher with the support of the two research assistants in the field of mathematics personally administered the instrument to the students who formed the respondents. Relevant information was provided to the respondents for accurate responses while the completed questionnaires were retrieved immediately. The completion of the informed consent form helped to document their willingness to participate in the study and address ethical issues related to their participation in the study.

\section{Data Analysis and Result}

Both descriptive and inferential statistics were employed in the analysis of the collected data. Three research questions were answered using frequency counts and percentages while only one hypothesis $1\left(\mathrm{HO}_{1}\right)$ formulated was tested using Chi-square $\left(\chi^{2}\right)$ statistical tool. The hypothesis was tested at 0.05 level of significant. For the purpose of analysis, very difficult, difficult and moderately difficult were merged and classified as difficult while not difficult was regarded as easy. This answers research questions 1,2 and 3.

Research Question 1: What are the geometry concepts perceived difficult to learn by senior school students in Ekiti State, Nigeria?

Table 1 shows frequency counts and the percentages of the number of respondents for geometry concepts perceived difficult to learn by the students. Concepts for which percentage response for difficulty falls below $60 \%$ are grouped as not difficult (easy) and concepts for which percentage difficulty is $60 \%$ or above are grouped as difficult. On the basis of this, out of 23 concepts, 8 concepts are perceived difficult to learn by the students. These are: congruent triangles, circle theorem, construction and locus, surface areas of solid figures, volume of solid figures, latitude and longitude, coordinates geometry and bearing and distances. Fifteen concepts are perceived not difficult (easy) by the students; they are: angles and lines, triangles, theorem on triangles, similar triangles, circles, polygons, quadrilaterals, lengths, areas and perimeters of plane figures, arcs and sectors of circles, chords and segments of circles, Pythagoras theorem, sine, cosine and tangent of right angled triangles, angles of elevation and depression, sine and cosine rule and graphs of sine and cosine functions.

Table 1: Percentage Difficulty Level of Geometry Concepts

\begin{tabular}{|c|c|c|c|}
\hline $\mathbf{S} / \mathbf{N}$ & $\begin{array}{l}\text { Fre } \\
\text { perc } \\
\text { resp } \\
\text { con }\end{array}$ & $\begin{array}{l}\text { ncy counts and } \\
\text { ages of No of } \\
\text { lents of difficult } \\
\text { s }\end{array}$ & $\begin{array}{l}\text { Frequency counts and } \\
\text { percentages of No of } \\
\text { respondents of not difficult } \\
\text { (Easy) concepts }\end{array}$ \\
\hline & Plane Geometry & & \\
\hline 1. & Angles and lines & $139(27.80 \%)$ & $361(72.20 \%)$ \\
\hline 2. & Triangles & $107(21.40 \%)$ & $393(78.60 \%)$ \\
\hline 3. & Theorems on triangles & $270(54.00 \%)$ & $230(46.00 \%)$ \\
\hline 4. & Similar triangles & $293(58.60 \%)$ & $207(41.40 \%)$ \\
\hline 5. & Congruent triangles & $347(69.40 \%)$ & $153(30.60 \%)$ \\
\hline 6. & Circles & $110(22.00 \%)$ & $390(78.00 \%)$ \\
\hline 7. & Polygons & $163(32.60 \%)$ & $337(67.40 \%)$ \\
\hline 8. & Quadrilaterals & $217(43.40 \%)$ & $283(56.60 \%)$ \\
\hline 9. & Circle theorems & $382(76.40 \%)$ & $118(23.60 \%)$ \\
\hline 10. & $\begin{array}{l}\text { Construction and locus } \\
\text { Mensuration }\end{array}$ & $448(89.60 \%)$ & $52(10.40 \%)$ \\
\hline \multirow[t]{2}{*}{11.} & Lengths, Areas and & & \\
\hline & Perimeter of plane figures & $183(36.60 \%)$ & $317(63.40 \%)$ \\
\hline 12. & Arcs and sectors of circles & $229(45.80 \%)$ & $271(54.20 \%)$ \\
\hline 13. & Chords and segments of circles & $249(49.80 \%)$ & $251(50.20 \%)$ \\
\hline 14. & Surface areas of solid figures & $380(76.00 \%)$ & $120(24.00 \%)$ \\
\hline 15. & Volume of solid figures & $362(72.40 \%)$ & $138(27.60 \%)$ \\
\hline 16. & Latitude and longitude & $364(72.80 \%)$ & $136(27.20 \%)$ \\
\hline 17. & $\begin{array}{l}\text { Coordinates geometry } \\
\text { Trigonometry }\end{array}$ & $418(83.60 \%)$ & $82(16.40 \%)$ \\
\hline 18. & Pythagoras theorem & $213(42.60 \%)$ & $287(57.40 \%)$ \\
\hline 19. & Sine, cosine and tangent of & & \\
\hline
\end{tabular}


Geometry Concepts in Mathematics Perceived Difficult To Learn By Senior Secondary School ..

Right angled triangle

$36(27.20 \%)$

$364(72.80 \%)$

20. Angles of elevation and

Depression

$237(47.40 \%)$

$263(52.60 \%)$

$383(76.60 \%)$

$117(23.40 \%)$

21. Bearings and Distances

$159(31.80 \%)$

$341(68.20 \%)$

23. Graphs of sine and cosine

Functions

$294(58.80 \%)$

$206(41.20 \%)$

Research Question 2: What are the plausible causes of the perceived difficulty of geometry concepts?

Table 2 shows the frequency counts and the percentage of reasons adduced by students in concepts perceived difficult to learn. It was discovered that unavailability of instructional materials/insufficient time has the highest percentage of $33.40 \%$ as the major reason for perceiving the concepts difficult to learn. Next to this is the teachers' method of instruction $(27.00 \%)$, complexity which is $16.80 \%$, students' gender $(12.00 \%)$ while misconception of concepts has the lowest percentage $(10.80 \%)$ of the reasons for perceiving the concepts difficult to learn.

Table 2 : Ranking of Reasons Adduced by Students in Concepts Perceived Difficult to Learn in Descending

\begin{tabular}{llll}
\multicolumn{4}{c}{ Order } \\
\hline S/N Reasons & Frequency Counts & Percentage (\%) & Rank
\end{tabular}

1. Teachers' method

of instruction

$27.00 \%$

$2^{\text {nd }}$

2. Unavailability of

Instructional Materials /

Insufficient time allocation

3. Students' gender

167

$33.40 \%$

60

$12.00 \%$

5. Complexity

$16.80 \%$

84

$10.80 \%$

concepts

54

$1^{\text {st }}$

$4^{\text {th }}$

$3^{\text {rd }}$

$5^{\text {th }}$

Research Question 3: What is the degree of the level of difficulty of geometry concepts?

Table 3 shows frequency counts and the number of the respondents of difficulty of geometry concepts. Frequency counts and percentage of difficult concepts is $6083(52.90 \%)$, while frequency counts and percentage of not difficult (Easy) concepts is 5417 (47.10\%) which gives a total frequency counts and percentage of 11500 (100\%). The degree of the level of difficulty of difficult geometry concepts is $52.90 \%$ while that of not difficult (Easy) is $47.10 \%$. This means that the degree of perceived difficult geometry concepts is higher than those that are perceived not difficult (Easy) to learn by the students.

Table 3: Degree of the Level of Difficulty of Geometry Concepts

\begin{tabular}{|c|c|c|c|}
\hline \multirow[t]{2}{*}{$\mathbf{S} / \mathbf{N}$} & Concepts & Frequency counts and & Frequency counts and \\
\hline & & $\begin{array}{l}\text { No of respondents of } \\
\text { difficult concepts }\end{array}$ & $\begin{array}{l}\text { No of respondents of } \\
\text { not difficult (Easy) } \\
\text { concepts }\end{array}$ \\
\hline
\end{tabular}

\section{Plane Geometry}

1. Angles and lines 139

2. Triangles 107

$\begin{array}{ll}139 & 361\end{array}$

3. Theorems on Triangles 270

4. Similar triangles 293

5. Congruent triangles 347

6. Circles 110

7. Polygons 163

8. Quadrilaterals 217

9. Circle theorems 382

10. Construction and locus 448

Mensuration

11. Lengths, Areas and Perimeter of plane figures 183

393

230

$\begin{array}{ll}1103 & 337\end{array}$

283

118

52

12. Arcs and sectors of circles

229

317

271 
Geometry Concepts in Mathematics Perceived Difficult To Learn By Senior Secondary School ..

13. Chords and segments of circles

14. Surface areas of solid figures 380

15. Volume of solid figures

16. Latitude and longitude

17. Coordinates geometry

18. Pythagoras theorem

19. Sine, cosine and tangent of right angled triangle

20. Angles of elevation and Depression

21. Bearings and Distances

22. Sine and cosine rule

23. Graphs of sine and cosine functions
249

362

364

418

213

136

237

383

159

294

$6083(52.90 \%)$
251

120

138

136

82

287

364

263

117

341

206

$5417(47.10 \%)$

Research Question 4: Does gender influence students perception of difficult geometry concepts?

HO$_{1}$ : There is no significant difference in the number of geometry concepts perceived difficult by male and female students.

Table 4reveals that the $\chi_{c a l}^{2}=28.02$ while the $\chi_{\text {tab }}^{2}=7.815$ with $\mathrm{df}=3$ at the level of significance of 0.05 .

Since the $\chi_{\text {cal }}^{2}$ value $>\chi_{\text {tab }}^{2}$ value, hypothesis 1 is rejected. This implies that there is a significant difference in the number of geometry concepts perceived difficult to learn by male and female students in favour of female students. This finding also provides an answer to research question 4.That is to say gender influences students' perception of difficult geometry concepts.

Table 4 : Chi-square Analysis Showing Responses of Male and Female Students on the Level of Difficult Geometry Concepts

\begin{tabular}{lllllllll}
\hline Gender & VD & D & MD & ND & DF & $\chi_{\text {cal }}^{2}$ & $\chi_{\text {tab }}^{2}$ & Remark \\
\hline \multirow{2}{*}{ Male } & 883 & 980 & 1054 & 2352 & 3 & 28.02 & 7.815 & Significant \\
& 809.59 & 959.87 & 1017.60 & 2481.93 & & & & \\
Female & 884 & 1115 & 1167 & 3065 & & & \\
& 957.41 & 1135.13 & 1203.40 & 2935.07 & & & \\
\end{tabular}

\section{Discussion}

The findings of this study revealed that, students perceived eight geometry concepts out of twenty-three concepts presented to them difficult to learn. These were: congruent triangles, circle theorem, construction and locus, surface areas of solid figures, volume of solid figures, latitude and longitude, coordinates geometry and bearing and distances. The finding is in line with Adegun and Adegun (2013) who revealed that construction and locus, longitude and latitude were perceived difficult topics to learn by students. Fifteen concepts were perceived not difficult (easy) by the students; which were: angles and lines, triangles, theorem on triangles, similar triangles, circles, polygons, quadrilaterals, lengths, areas and perimeters of plane figures, arcs and sectors of circles, chords and segments of circles, Pythagoras theorem, sine, cosine and tangent of right angled triangles, angles of elevation and depression, sine and cosine rule and graphs of sine and cosine functions.

Reasons given by the students for perceiving the geometry concepts difficult were: unavailability of instructional materials/ insufficient time allocation $167(33.40 \%)$ which had the major reason, teachers' method of instruction 135 (27.00\%), Complexity 84 (16.80\%), students' gender $60(12.00 \%)$ and misconception of concepts $54(10.80 \%)$ which had the least reason of perceiving the geometry concepts difficult. This finding is in agreement with the earlier results of Telima (2011) who found that students' difficulty in geometry were caused by non-availability of instructional materials and teachers' method of instruction.

Degree of the level of difficulty of geometry concepts perceived difficult by the students was 6083 $(52.90 \%)$ while that of not difficult (easy) was 5417 (47.10\%).

There was a significant difference in the number of geometry concepts perceived difficult to learn by male and female students in favour of female students. This implied that female students do better in geometry than male students. The finding agrees with Kurumeh (2004) and Gimba (2006) who found that female students 
performed better than male students when exposed to geometry, mensuration and 3-dimensional mathematics instructional material respectively.

\section{Conclusion}

From the results, the following conclusions were made:

i. Eight geometry concepts were perceived difficult to learn by the students while fifteen concepts were perceived not difficult to learn by the students.

ii. The causes of difficulty in the learning of concepts in geometry could be traceable to teachers' method of instruction, unavailability of instructional materials/ insufficient time allocation, students' gender, complexity, and misconception of concepts.

iii. The degree of the level of difficulty of difficult geometry concepts was $52.90 \%$ while that of not difficult (easy) was $47.10 \%$.

iv. Students' gender had a significant influence on the number of geometry concepts perceived difficult by male and female students in favour of female students. This implied that female students do better in geometry than male students.

\section{Recommendations}

Based on these findings, the following recommendations are considered appropriate:

1. The identified difficult geometry concepts in mathematics by the students should be taught by using appropriate teachers' method of instruction.

2. Federal and state ministry of education should provide relevant instructional materials to various schools for teaching of concepts in geometry.

3. School authorities should allocate sufficient time for mathematics especially geometry concepts that students perceived difficult to learn.

4. Government and schools should organize workshops and seminars for teachers on how to teach the difficult geometry concepts in mathematics effectively.

5. Curriculum planners should endeavour to arrange the geometry concepts in a way that will not be too complex for teachers to teach and to understand by students.

\section{References}

[1]. J. O. Ayinla, Effects of Teachers instructional strategy pattern on senior school students' performance in mathematics word problem in Ondo, Nigeria, Unpublished M. Ed. Thesis, University of Ilorin,Ilorin, Nigeria, 2011.

[2]. $\quad$ S. P. Michael, "Mathematics." Microsoft $®$ Student Encarta, 2008.

[3]. B. O. Soyemi, and O. S. Jegede, Student dictionary of mathematics (Revised ed.). (Wiseword Associates Publication, 2000$)$ 11-23.

[4]. D. Douglas, Dictionary of mathematics (3rd ed.). (New York, NY: Barron's Educational Series, Inc, 2009).

[5]. M. F. Salman, Teachers' identification of the difficult levels of topics in the primary school mathematics curriculum. Journal of Mathematical Association of Nigeria, 30(1), 2005, 20-28.

[6]. Federal Republic of Nigeria, National policy on education, (6th ed.). (Lagos: Federal Government Press, 2013).

[7]. J. O. Kekere, Effective counselling of students on the study of mathematical sciences. Paper presented at the Mathematics Clinic for Ekiti State Secondary School Mathematics Teachers, Ado-Ekiti, 2008

[8]. I. K. Adegun, and B. O. Adegun, Students and teachers' views of difficult areas in mathematics syllabus: Basic equirement for science and engineering education. Journal of Education and Practice, 4(12), 2013, 235-243.

[9]. O. F. Betiku,. Causes of mass failure in mathematics examinations among students. A commissioned paper presented at Government Secondary School, Karu, Abuja, 2000.

[10]. National Mathematical Centre, NMC, Abuja, Mathematics improvement programme. Retrieved on $26^{\text {th }} \mathrm{July}^{\mathrm{a}}$, 013 from www.nmcabuja.org/mathematics improvement programmes.html, 2009.

[11]. J. C. Amazigo, Mathematics phobia diagnosis and prescription. National Mathematical Centre first annual lecture, Abuja, 2000.

[12]. West African Examinations Council, WAEC, West African Examinations Council Chief Examiners' Report, 2007.

[13]. West African Examinations Council, WAEC, West African Examinations Council Chief Examiners' Report,2008.

[14]. West African Examinations Council, WAEC, West African Examinations Council Chief Examiners' Report,2009.

[15]. West African Examinations Council, WAEC, West African Examinations Council Chief Examiners' Report, 2010.

[16]. West African Examinations Council, WAEC, West African Examinations Council Chief Examiners' Report, 2011.

[17]. M. M. Paulina, Perspectives on the teaching of geometry for the $21^{\text {st }}$ century (Dordrecht: Kluwer, 2007).

[18]. M. F. Salman, Active learning techniques (ALT) in mathematics workshop; Nigerian primary school teachers' assessment. International Electronic Journal of Mathematics Education, 4 (1), 2009, 23-35.

[19]. M. Battista, Geometry results from the third international mathematics and science study. Teaching Children Mathematics, 5(6), 1999, 367-373.

[20]. Volderman, How Maths work. (London: Dorling Kindersley, 1998). G. Sunzuma, M. Masocha, and N. Zezekwa, Secondary school students' attitudes towards their learning of geometry: A survey of Bindura urban secondary schools. Greener Journal of Educational Research, 3(8), 2012, 402- 410.

[21]. M. Mason, The van Hiele levels of geometric understanding. Retrieved from http:/jwilson.coe.uga.edu/EMAT8990/GEOMETRY, 2002.

[22]. I. Noraini, Teaching and learning of mathematics: Making sense and developing cognitive abilities (Perak: Utusan Publication Sdn. Bhd. Nigeria, 2006).

[23]. U. J. Uduosoro, Perceived and actual learning difficulties of students in secondary school mathematics.

[24]. International Multidisciplinary Journal, Ethiopia, 5 (5), 2011, 357-366.

[25]. A. Telima, Problems of teaching and learning of geometry in secondary schools in River State, Nigeria.

DOI: 10.9790/7388-0701018390 $\quad$ www.iosrjournals.org $\quad 89 \mid$ Page


[26]. International Journal of Emerging Science, 1(2), 2011, 143-152.

[27]. O. Aysen, Misconceptions in geometry and suggested solutions for seventh grade students. International Journal of New Trends in Arts, Sports and Science Education, 1(4), 2012, 1-13.

[28]. Nigerian Educational Research and Development Council, NERDC, Teachers' guide for the revised 9-ear basic education curriculum mathematics for JS1-3 (Lagos: NERDC Press, 2012) 62-67.

[29]. B. F. Azuka, O. Jekayinfa, D. Durojaye, and S. O. Okwoza, Difficulty levels of topics in the new senior secondary school mathematics curriculum as perceived by mathematics teachers of federal unity schools in Nigeria. Journal of Education and Practice, 4(17), 2013, 23-25.

[30]. D. A. Abdul-Raheem, Ratings of the difficulty levels of senior school mathematics topics by teachers and students in Ibadan, Nigeria, Unpublished M. Ed Thesis, University of Ilorin, Ilorin, Nigeria, 2012.

[31]. M. Baharvand, A comparison of the effectiveness of computer- assisted instruction versus traditional approach o teaching geometry, Unpublished master's thesis, California State University, USA, 2001.

[32]. U. E. Etukudo, The effect of computer-assisted instruction on gender and performance of junior secondary school students in mathematics. Journal of Mathematical Association of Nigeria, 27 (1), 2002, 1-8.

[33]. M. S. Omirin, Issues in the implementation of continuous assessment in Ekiti State secondary schools. A paper presented at the Inaugural Seminar of Women in Academics, University of Ado - Ekiti, 2009.

[34]. S. O. Olagunju, Sex, age, and performance in mathematics. Journal of Mathematical Association of Nigeria, 26 (1), 2001, 8-16.

[35]. B. E. Gbodi, and A. M. Laleye, Effects of videotaped instruction on learning of integrated science. Journal of Research in Curriculum and Teaching, 1 (1), 2006, 10-19.

[36]. S. O. Adebule, Gender differences on a locally standardized anxiety rating scale in mathematics for Nigerian Secondary schools, Nigerian Journal of Counselling and Applied Psychology, 2(1), 2004, 22-28.

[37]. P. O. Abiam, and J. K. Odok, Factors in students' achievement in different branches of secondary school mathematics. Journal of Education and Technology, 1(1), 2006, 161-168.

[38]. D. M. Burton, The history of mathematics: An Introduction (4th ed.). (Boston: WCB McGraw-Hill, 1999).

[39]. M. S. C. Kurumeh, Effect of ethno-mathematics teaching approach on students achievement and interest in geometry and mensuration, Unpublished Ph. D dissertation, University of Nigeria, Nsukka, 2004.

[40]. R. W. Gimba, Effects of computer package on achievement, retention and interest in set theory among secondary school students in Niger state, Unpublished Ph. D dissertation, University of Nigeria, Nsukka, 2013. 